\title{
¿Cómo cambiar hacia sociedades sostenibles? Reflexiones sobre biomímesis y autolimitación ${ }^{1}$
}

\author{
JORGE RIECHMANN ${ }^{2}$ \\ Universidad de Barcelona
}

RESUMEN. Vivimos dentro de sistemas socioeconómicos humanos demasiado grandes en relación con la biosfera que los contiene, por una parte; y sistemas mal adaptados, sistemas humanos que encajan mal en los ecosistemas naturales. El problema de escala reclama un movimiento de autolimitación por parte de las sociedades humanas, que podríamos concebir (en términos de economía política) bajo la idea de gestión global de la demanda; el problema de estructura exige una reconstrucción de la tecnosfera de acuerdo con principios de biomímesis.
ABSTRACT. We livein socio-economical systems which are too large in relation to the biosphere which contains them, on the one hand, and on the other, we live in badly adapted systems, that is, human systems not well fitted into the natural ecosystems. The scale problem calls for a move toward self-limitation by human societies, which (in terms of political economy) could be thought of as global demand management; the structural problem demands a reconstruction of the technosphere according to biomimicry principles.

${ }^{1}$ Artículo basado en la conferencia inaugural del IV Congreso Nacional de Estudiantes y Licenciados en Ciencias Ambientales, Almería, 21 de octubre de 2004

2 Jorge Riechmann (Madrid, 1962) es poeta, ensayista y profesor titular de filosofía moral en la Universidad de Barcelona; actualmente trabaja como director (en funciones) del Observatorio de la Sostenibilidad en España (con sede en la Universidad de Alcalá de Henares). Es socio de la Sociedad Española de Agricultura Ecológica (SEAE), miembrø del Consejo de Greenpeace España y afiliado a Ecologistas en Acción. Ha traducido extensamente a poetas como René Char y dramaturgos como Heiner Müller.

Entre sus últimas obras publicadas destacan los ensayos de tema ecológico Necesitar, desear, vivir. Sobre necesidades, desarrollo humano, crecimiento económico y sustentabilidad (Madrid, Los Libros de la Catarata, 1998), Todo tiene un límite (Madrid, Debate, 2001), Cuidar la T(t)ierra (Barcelona, Icaria, 2003) y Transgénicos: el haz y el envés (Madrid, Los Libros de la Catarata, 2004); la traducción de Indagación de la base y de la cima de René Char (Madrid, Árdora, 1999), por la que obtuvo el premio de traducción Stendhal 2000; los volúmenes de reflexión sobre poética Canciones allende lo humano (Madrid, Hiperión, 1998) y Una morada en el aire (Barcelona, Libros del Viejo Topo, 2003); así como los poemarios El día que dejé de leer EL PAÎ́S (Madrid, Hiperión, 1997), Muro con inscripciones (Barcelona, DVD, 2000), Desandar lo andado (Madrid, Hiperión, 2001), Poema de uno que pasa (Valladolid, Fundación Jorge Guillén, 2003), Un zumbido cercano (Madrid, Calambur, 2003) y Anciano ya y nonato todavía (Tegueste, Eds. El Baile del Sol, 2004).

En los últimos años, ha ido formulando la vertiente ética de su filosofía ecosocialista en una «trilogía de la autocontención» que componen los volúmenes Un mundo vulnerable (Madrid, Los 


\section{Cuatro rasgos básicos de nuestra situación}

Llevo algún tiempo ${ }^{3}$ intentado desarrollar un análisis de la cuestión sostenibilidad/desarrollo sostenible que parte de las siguientes cuatro premisas (o rasgos básicos de nuestra situación actual):

1. Hemos «llenado» el mundo, saturándolo en términos de espacio ecológico (como nos ha hecho ver el economista ecológico Herman E. Daly desde hace más de dos decenios).

2. Nuestra tecnosfera está mal diseñada, y por eso — como nos enseñó el biólogo Barry Commoner hace más de treinta años- se halla «en guerra» con la biosfera.

3. Además, somos terriblemente ineficientes en nuestro uso de las materias primas y la energía (como han mostrado, entre otros, los esposos Lovins y Ernst Ulrich von Weizsäcker en Factor 4 ).

4. Por último, nuestro poderoso sistema ciencia-técnica (que ahora podemos cabalmente llamar tecnociencia, tal y como insiste Javier Echeverría) anda demasiado descontrolado.

De cada uno de esos rasgos puede deducirse -en un sentido muy laxo del término deducción - un importante principio para la reconstrucción ecológica de los sistemas humanos, esto es, para avanzar hacia sociedades ecológicamente sostenibles:

Hemos «llenado» el mundo $\rightarrow$ principio de gestión generalizada de la demanda

Nuestra tecnosfera está mal diseñada $\rightarrow$ principio de biomímesis o ecomímesis

Somos terriblemente ineficientes $\rightarrow$ principio de ecoeficiencia

Nuestra poderosa tecnociencia anda demasiado descontrolada $\rightarrow$ principio de precaución

A estas alturas de los debates sobre sostenibilidad, los dos últimos principios - ecoeficiencia y precaución - deberían resultarnos familiares; en cambio, los dos primeros resultan menos conocidos, y por ello centraré este artículo en ambos. Pero antes de ir a ello señalaré dos problemas:

Libros de la Catarata, 2000), Todos los animales somos hermanos (Universidad de Granada, 2003) y Gente que no quiere viajar a Marte (Madrid, Los Libros de la Catarata, 2004).

${ }^{3}$ Remito a mi «trilogía de la autocontención»: Un mundo vulnerable (Madrid, Los Libros de la Catarata, 2000), Todos los animales somos hermanos (Universidad de Granada, 2003) y Gente que no quiere viajar a Marte (Madrid, Los Libros de la Catarata, 2004). 
(A) Hace falta práctica humana basada en los cuatro principios para avanzar hacia sociedades ecológicamente sostenibles, pero, de los cuatro, sólo el principio de ecoeficiencia encaja de forma más o menos «natural» con la dinámica del capitalismo. Ésa es la razón de que «desarrollo sostenible»-que, como sabemos, es un concepto sobre cuyo contenido existen intensas controversias ${ }^{4}$ - sea entendido por las empresas, y en general por las autoridades públicas, de manera muy reductiva, en términos de ecoeficiencia, y de casi nada más.

(B) Esos cuatro principios bastarían - creo- para orientar hacia la pacificación nuestras relaciones con la naturaleza, pero no para lograr una ciudad humana habitable. Una sociedad podría poner en práctica los cuatro principios, y mantener, sin embargo, grados extremos de desigualdad social o de opresión sobre las mujeres. Podrían existir sociedades ecológicamente sustentables que fuesen al mismo tiempo ecofascistas y/o ecomachistas $^{5}$.

Por eso sabemos que, al menos desde los valores emancipatorios de la izquierda, tenemos que defender además un fuerte principio de igualdad social (o mejor, la vieja buena tríada de la Gran Revolución de 1789: libertad + igualdad + fraternidad o solidaridad, todos ellos adecuadamente corregidos por la mirada feminista sobre la realidad). No nos basta con una sociedad ecológicamente sustentable: deseamos una sociedad ecosocialista ${ }^{6}$.

Traer a colación la tríada de valores liberté, égalité, fraternité supone reconocer la suprema importancia de la cuestión de la alteridad: en nuestra relación con el otro se juegan los asuntos ético-políticos más básicos de todos (en ello han insistido con lucidez Emmanuel Levinas y Zygmunt Bauman), sobre todo cuando tenemos presente que no se trata solamente del otro humano, sino también del otro animal ${ }^{7}$.

\section{Sobre comunidades de vecinos en bloques de viviendas}

Durante el siglo Xx tuvo lugar un acontecimiento decisivo, cuyas consecuencias estamos aún lejos de haber asimilado. La humanidad, que durante milenios vivió dentro de lo que en términos ecológicos puede describirse

\footnotetext{
${ }^{4}$ Cuestión que abordé, en su momento, en «Desarrollo sostenible: la lucha por la interpretación», en Jorge Riechmann y otros: De la economía a la ecología, Madrid, Trotta, 1995.

${ }_{5}^{5}$ Nunca me cansaré de recomendar la lectura de dos libros importantes: Carl Amery, Auschwitz, ¿comienza el siglo XXI? Hitler como precursor, Madrid, Turner-FCE, 2002. Y Susan George, El informe Lugano, Barcelona, Icaria, 2001.

${ }^{6}$ Lo que entiendo por ello comencé a ponerlo por escrito en un libro escrito a medias con Paco Fernández Buey y publicado en 1996: Francisco Fernández Buey y Jorge Riechmann, Ni tribunos. Ideas y materiales para un programa ecosocialista, Madrid, Siglo XXI, 1996.

7 Jorge Riechmann, Todos los animales somos hermanos, Universidad de Granada, 2003.
} 
como un «mundo vacío», ha pasado a vivir en un «mundo lleno» ${ }^{8}$. Hasta puede fecharse, con cierta exactitud, el momento en que las demandas colectivas de la humanidad (que extrae recursos de las fuentes de la biosfera y deposita residuos y contaminación en sus sumideros, además de depender de las funciones vitales básicas más generales que proporciona la biosfera) superaron por vez primera la capacidad regenerativa de la Tierra: según un grupo de científicos dirigidos por Mathis Wackernagel -uno de los creadores del concepto de «huella ecológica», a mediados de los años noventaeso sucedió hacia 1980, y veinte años más tarde nuestras demandas superaban esa biocapacidad de la Tierra en un $20 \%$ aproximadamente ${ }^{9}$. Nos hallamos, entonces, en una situación crecientemente insostenible.

Ahora vivimos, por consiguiente, en un «mundo lleno» o saturado ${ }^{10}$. La época en que las sociedades humanas y sus economías eran relativamente pequeñas con respecto a la biosfera, y tenían sobre ésta relativamente poco impacto, pertenece irrevocablemente al pasado. El efecto acaso más importante de este cambio - que no resultaría exagerado calificar con el algo pedante adjetivo «epocal»- es que vuelve a situarnos cara a cara a todos los seres humanos. Me explicaré.

Una metáfora adecuada puede ser la contraposición entre habitar un chalé aislado (el modelo «la casa de la pradera», digamos), o un piso de un bloque de viviendas. En el primer caso, puede uno hacerse la ilusión de que su forma de vivir no afecta a los demás, y —si cuenta con recursos suficientes- organizarse básicamente sin tener en cuenta a los otros. En el segundo caso, ello es manifiestamente imposible. Ahora bien: para generalizar en nuestra biosfera la manera de vivir que metaforiza «la casa de la pradera», tendríamos que ser muy pocos y muy ricos, y sabemos que ése no es el caso a comienzos del siglo XXI (somos 6.600 millones de habitantes en 2004, con cientos de millones de pobres de solemnidad y un nivel aberrante de desigualdad social a escala planetaria). Estamos abocados entonces a un modelo de convivencia que, a escala planetaria, se parecerá más a la de la comunidad de vecinos en el bloque de viviendas ${ }^{11}$.

\footnotetext{
${ }^{8}$ Ha sido el economista ecológico Herman E. Daly quien más lúcidamente ha argumentado que ya no nos encontramos en una «economía del mundo vacío», sino en un «mundo lleno» o saturado en términos ecológicos (porque los sistemas socioeconómicos humanos han crecido demasiado en relación con la biosfera que los contiene): Véase Daly y John B. Cobb, Para el bien común, México, FCE, 1993, p. 218. También Daly, «De la economía del mundo vacío a la economía del mundo lleno», en Robert Goodland, Herman Daly, Salah El Serafy y Bernd von Droste: Medio am. biente y desarrollo sostenible; más allá del Informe Brundtland, Madrid, Trotta, 1997, pp. 37-50.

9 Mathis Wackernagel y otros, «Tracking the ecological overshoot of the human economy», Proceedings of the National Academy of Sciences, 9 de julio de 2002, pp. 9266-9271.

${ }^{10}$ Lo justifica convincentemente, por ejemplo, Robert Goodland, «La tesis de que el mundo está en sus límites», en Robert Goodland Herman Daly, Salah El Serafy y Bernd von Droste: Medio ambiente y desarrollo sostenible; más allá del Informe Brundtland, Madrid, Trotta, 1997, pp. 19-36.

${ }_{11}$ Siempre que conservemos entre nuestros valores el aprecio por la justicia sin el cual «condición humana» se volvería una palabra huera. Si no fuera así, son concebibles modelos de organiza-
} 
A cualquiera que haya vivido las aburridas y muchas veces difíciles reuniones de los vecinos de la escalera, donde hay que aguantar las excentricidades de la del tercero derecha, las inaguantables pretensiones del morador del ático y el aburrido tostón que nos endilga el del segundo izquierda, la perspectiva podrá parecerle descorazonadora. Y, sin embargo, ésa es la situación en que nos hallamos, y no va a modificarse ni un ápice por intentar ignorarla practicando la política del proverbial avestruz. Tendremos que mejorar la calidad de la convivencia con los vecinos de nuestra escalera, darnos buenas reglas para el aprovechamiento compartido de lo que poseemos en común, y educarnos mutuamente con grandes dosis de paciencia, tolerancia y liberalidad. Estamos obligados a llegar a entendernos con esos vecinos, so pena de una degradación catastrófica de nuestra calidad de vida... o quizá, incluso, de la desaparición de esa gran comunidad de vecinos que es la humanidad, cuya supervivencia a corto plazo en el planeta Tierra no está ni mucho menos asegurada.

\section{La nueva interdependencia}

La metáfora se ajusta bien a la situación en que nos hallamos, como inquilinos de la biosfera que es nuestra casa común, a principios del siglo XXI. En este «mundo lleno» en términos ecológicos, no es posible ya imaginar ningún tipo de «espléndido aislamiento», semejante al del opulento habitante del chalé aislado. La consecuencia más importante de la finitud del planeta es la estrecha interdependencia humana. En otro lugar he caracterizado esta situación como «la época moral del largo alcance» ${ }^{12}$, pues las consecuencias de nuestros actos llegan más lejos —en el tiempo y en el espacio- que en ninguna fase anterior de la historia humana.

Las decisiones de uno, ya sea un individuo, uná colectividad o una nación, tienen necesariamente consecuencias, a mayor o menor plazo, para todos los otros. Cada uno incide entonces en las decisiones de todos. Esta sujeción puede parecer penosa. En realidad, es la clave para el acceso de todos a un estatuto verdaderamente humano. Intentar escapar de ella sería renunciar a una riqueza esencial, nuestra humanitud, que no recibimos de la naturaleza, sino que la construimos nosotros ${ }^{13}$.

ción socioecológica donde unos pocos viven en espléndidos chalés protegidos por alambre de espinos, campos minados y ejércitos privados - por seguir con nuestra metáfora de antes-, mientras que la mayoría se hacina en míseras chabolas en las favelas circundantes. Es decir, el tipo de paisaje urbano que ya encontramos en diferentes zonas de nuestro planeta...

${ }_{12}$ Jorge Riechmann, Un mundo vulnerable, segunda edición, Madrid, Los Libros de la Catarata, en prensa.

13 Albert Jacquard, «Finitud de nuestro patrimonio», Le Monde Diplomatique (edición españo1a), 103 , mayo de 2004 , p. 28 . 
Somos mucha gente viviendo dentro de un espacio ambiental limitado. Las reglas de convivencia que resultan adecuadas para esta situación son diferentes, sin duda, de aquellas que hemos desarrollado en el pasado, cuando éramos pocos seres humanos viviendo dentro de un espacio ambiental que nos parecía ilimitado. Pensemos, por ejemplo, en que, todavía hoy, las subvenciones para actividades que destruyen el medio ambiente (como la quema de combustibles fósiles, la tala de los bosques, la sobreexplotación de acuíferos o la pesca esquilmadora) alcanzan en todo el mundo la increíble cifra de 700.000 millones de dólares cada año ${ }^{14}$ : se trata, evidentemente, de una situación heredada de tiempos pasados, cuando en un «mundo vacío» podía tener sentido incentivar económicamente semejantes actividades extractivas. En un «mundo lleno» resulta suicida: hacen falta nuevas reglas de convivencia (gravar tales actividades con ecoimpuestos o tasas ambientales en lugar de subvencionarlas, por ejemplo).

Un asunto que en la nueva situación se torna imperioso es la necesidad de incrementar la cantidad y la calidad de la cooperación. El cowboy del Lejano Oeste podía intentar prosperar en solitario (aunque quizá al precio de una vida empobrecida, breve y violenta); para el ser humano del siglo XXI esa opción ni siquiera puede plantearse.

Somos muchos, y estamos destinados a vivir cerca unos de otros. Tal situación no es necesariamente una condena: podemos y debemos transformarla en una ocasión para mejorar juntos. Pero eso nos exige pensar de otra manera sobre los valores de lo individual y lo colectivo, y en cierta forma nos convoca a reinventar lo colectivo.

\section{Una fase de reflexividad acrecentada}

Las reglas de gestión, los criterios económicos y los principios de convivencia que han de regir en un «mundo lleno» son diferentes a los que desarrollamos en el pasado para un "mundo vä́cío». Como bien saben el matemático o el teórico de sistemas, el cambio en las «condiciones en los límites» transforma el equilibrio del sistema.

Cuando alcanzamos los límites del planeta, todo parece volver a nosotros en una suerte de «efecto bumerán» ubicuo y multiforme, y se vuelve imperiosa la necesidad de organizar de una manera radicalmente distinta nuestra manera de habitarlo. En todas partes retornan a nosotros los efectos de nuestra actividad - a menudo de forma muy problemática-. Podríamos aducir muchos ejemplos, pero uno importante es el de los desechos y residuos que generamos. Los sistemas locales de gestión de la contaminación nos hacen creer que nos desembarazamos de las sustancias nocivas, pero en realidad lo

\footnotetext{
${ }^{14}$ Lester R. Brown: Plan B. Salvar el planeta: ecología para un mundo en peligro, Barcelona, Paidós, 2004, p. 307.
} 
que suele suceder es que las trasladamos más lejos, a menudo haciendo surgir en otro lugar problemas que pueden ser más graves que los iniciales. Y no encontramos ya centímetro cúbico de aire o agua, o gramo de materia viva, donde no podamos rastrear las trazas de nuestros sistemas de producción y consumo.

Veamos otro ejemplo. En un «mundo vacío», las sustancias tóxicas se diluyen, y podríamos quizá despreocuparnos de lo toxificados que están nuestros sistemas productivos; pero en un «mundo lleno» los tóxicos acaban siempre retornando a nosotros, produciendo daño. De ahí la importancia de propuestas como las que avanza la química verde ${ }^{15}$, que diseña procesos y productos químicos que eliminan (o reducen al máximo) el uso o la generación de sustancias peligrosas. Lo decisivo, aquí, es incorporar ya en la fase inicial de diseño la previsión de los riesgos que pueden surgir después, cuando el compuesto químico marcha a vivir su vida dentro de ecosistemas, sociosistemas, mercados y organismos vivos ${ }^{16}$. De nuevo vemos cómo producir en un «mundo lleno» exige un salto cualitativo en lo que a reflexividad se refiere: la anticipación de daños futuros obliga a intervenir en el momento de diseño inicial.

\section{LOS DOCE PRINCIPIOS DE LA QUÍMICA VERDE SEGÚN PAUL ANASTAS Y JOHN WARNER}

1. Evitar los residuos (insumos no empleados, fluidos reactivos gastados).

2. Maximizar la incorporación de todos los materiales del proceso en el producto acabado.

3. Usar y generar sustancias que posean poca o ninguna toxicidad.

4. Preservar la eficacia funcional, mientras se reduce la toxicidad.

5. Minimizar las sustancias auxiliares (por ejemplo, disolventes o agentes de separación).

6. Minimizar los insumos de energía (procesos a presión y temperatura ambiental).

7. Preferir materiales renovables frente a los no renovables.

15 Las ideas seminales de este movimiento fueron formuladas por Paul Anastas y Pietro Tundo a comienzos de los años noventa. Un manual básico es Paul T. Anastas y John C. Warner: Green Chemistry, Theory and Practice, Oxford University Press, 1998. Dos útiles introducciones breves: Terry Collins, «Hacia una química sostenible», y Ken Geiser, «Química verde: diseño de procesos y materiales sostenibles», ambos en Estefanía Blount, Jorge Riechmann y otros, Industria como naturaleza: hacia la producción limpia, Madrid, Los Libros de la Catarata, 2003. En España, el centro de referencia en química verde es el IUCT (Instituto Universitario de Ciencia y Tecnología, véase www.iuct.com), con sede en Mollet del Vallès, que entre otras iniciativas ha creado un programa interuniversitario de doctorado sobre química sostenible pionero en el mundo (participa en él una docena de universidades españolas: véase, por ejemplo, www.unavarra.es/organiza/pdf tpd_Quimica_Sostenible.pdf).

${ }_{16}$ Como introducción al ecodiseño puede servir Joan Rieradevall y Joan Vinyets, Ecodiseño y ecoproductos, Barcelona, Rubes Editorial, 2000. 
8. Evitar derivaciones innecesarias (por ejemplo, grupos de bloqueo, pasos de protección y desprotección).

9. Preferir reactivos catalíticos frente a reactivos estequiométricos.

10. Diseñar los productos para su descomposición natural tras el uso.

11. Vigilancia y control «desde dentro del proceso» para evitar la formación de sustancias peligrosas.

12. Seleccionar los procesos y las sustancias para minimizar el potencial de siniestralidad.

Fuente: Paul T. Anastas y John C. Warner: Green Chemistry, Theory and Practice, Oxford University Press, 1998, p. 30.

\section{Productividad en un «mundo lleno»}

Uno de los elementos determinantes de la Revolución Industrial fue el $g i$ gantesco salto en la productividad humana que permitió. La historia es bien conocida: la conjunción de una serie de procesos como la privatización de bienes comunes (las enclosures en el campo inglés), la acumulación primitiva de capital, ciertas mejoras técnicas, una creciente división del trabajo, una también creciente proletarización del campesinado, la mecanización intensiva y el uso masivo de una nueva fuente de energía (el carbón) condujeron a una transformación de los sistemas productivos que hizo crecer exponencialmente las capacidades productivas humanas. En la industria textil británica, lo que hacían doscientos obreros en $\mathbf{1 7 7 0}$ lo realizaba uno solo ya en 1812 , y esta poderosa tendencia al incremento constante de la productividad del trabajo ha proseguido desde entonces: en los últimos decenios, como es bien sabido, ha recibido nuevos impulsos (automatización, informatización, robotización). En definitiva, una tendencia histórica del capitalismo industrial ha sido producir cantidades crecientes de bienes y servicios con cantidades decrecientes de trabajo.

Ahora bien, los comienzos de la Revolución Industrial tuvieron lugar en un «mundo vacío» en términos ecológicos, y - consiguientemente - la preocupación por la productividad de las materias primas y la energía fue solamente marginal. Los recursos naturales y el capital natural se consideraban prácticamente «bienes libres». Ciertamente se han producido en los últimos dos siglos importantes avances en la productividad del factor productivo naturaleza, pero sólo como subproducto de otras búsquedas orientadas a aumentar los beneficios, y no como objetivo de una estrategia sistemática y deliberada.

La situación ha de cambiar radicalmente en un «mundo lleno». Observemos que la racionalidad económica requiere que se maximice la productividad del factor de producción más escaso. Ahora bien: entre los tres factores clásicos de producción - trabajo, capital y tierra/naturaleza-, a largo plazo 
- y ya en nuestro «mundo lleno»-la naturaleza es el factor de producción más escaso. En efecto: la fuerza de trabajo es reproducible si existen alimentos y recursos naturales; el capital es reproducible si existe trabajo y recursos naturales; pero la naturaleza no es reproducible de la misma forma. Existen recursos naturales - los combustibles fósiles, por ejemplo- que se están agotando irreversiblemente, los recursos renovables se vuelven en la práctica no renovables cuando se sobreexplotan, muchos ecosistemas están degradándose irreversiblemente. «La evolución de la economía humana ha conducido de una era en la que el capital manufacturado era el factor limitante para el desarrollo económico a otra era en la que el restante capital natural se ha convertido en el factor limitante» 17 .

En el «mundo vacío» de los comienzos de la industrialización, donde el factor trabajo escaseaba y el factor naturaleza abundaba, tenía sentido concentrarse en la productividad humana; en un «mundo lleno» en términos ecológicos, donde la situación es inversa (el factor trabajo abunda y el factor naturaleza escasea), hay que invertir en protección y restauración de la naturaleza, así como buscar incrementos radicales de la productividad con que la empleamos ${ }^{18}$. Es el importante tema de la ecoeficiencia ${ }^{19}$. Observamos de nuevo cómo cuando se ha «llenado» o saturado ecológicamente el mundo, han de cambiar las reglas básicas de juego (en este caso, las estrategias de producción de bienes y servicios) ${ }^{20}$.

17 Herman E. Daly, «From empty-world economics to full-world economics», en Robert Goodland, Herman Daly, Salah El Serafy y Bernd von Droste: Environmentally Sustainable Economic Development, París, UNESCO, 1991, p. 29.

18 Éste es el tema de libros importantes como Ernst Ulrich von Weizsäcker, L. Hunter Lovins y Amory B. Lovins: Factor 4. Duplicar el bienestar con la mitad de los recursos naturales (informe al Club de Roma), Barcelona, Galaxia Gutenberg-Círculo de Lectores, 1997; y Paul Hawken, L. Hunter Lovins y Amory B. Lovins: Natural Capitalism. Creating the Next Industrial Revolution, Boston-Nueva York, Little, Brown \& Co., 1999.

${ }^{19}$ La idea de llegar al desarrollo sostenible promoviendo la ecoeficiencia tiene una fuerte impronta empresarial (del «sector ilustrado» del empresariado multinacional), y fue promovida vigorosamente por el Business Council for Sustainable Development (BCSD, hoy WBSCD) en la antesala de la «Cumbre de Río» de 1992. Un buen texto reciente coordinado por el Instituto Wuppertal: Jan-Dirk Seiler-Hausmann, Christa Liedtke y Ennst Ulrich von Weizsäcker, Eco-efficiency and Beyond. Towards the Sustainable Enterprise, Sheffield, Greenleaf Publishing, 2004.

20 Me parece importante insistir en este punto precisamente en la España de 2004, cuando se ha generalizado el diagnóstico de que el modelo productivo de los últimos decenios está agotado y se buscan salidas por el lado de la productividad (véase, por ejemplo, el editorial de El País «Un modelo agotado», de 16 de agosto de 2004). El gobierno de José Luis Rodríguez Zapatero y —por ejemplo- - fuerzas sociales como los sindicatos CCOO y UGT comparten un análisis que más o menos es el siguiente: España tiene que sumarse al objetivo europeo de desarrollar una economía más productiva e innovadora, fortaleciendo el tejido productivo sobre la base de competir con calidad y valor añadido - y no en el ajuste de precios a la baja-, e incorporando los valores de sostenibilidad, estabilidad, seguridad e igualdad. Literalmente, CCOO se ha dado el objetivo de "promover un modelo de desarrollo sostenible, basado en la gestión adecuada de los recursos, en el conocimiento, en la inversión tecnológica, en la empresa innovada y socialmente responsable, y en la mejora de la productividad del factor trabajo» (Programa de Acción de CCOO aprobado en el 8.? Congreso Confederal, Madrid, 21 al 24 de abril de 2004, p. 24). 
Hasta hace un par de siglos, quizá sólo algunos decenios, podíamos pensar que el mundo estaba lleno de naturaleza y vacío de gente; hoy está lleno de gente y cada vez más vacío de naturaleza.

En un «mundo vacío», perseguir la expansión continua de la oferta puede tener sentido; en un mundo lleno es un desatino (pensemos en los conflictos contemporáneos relacionados con el abastecimiento de agua o de energía). Esto supone otro ejemplo importante de cómo cambian las reglas de juego (económico-sociales en este caso) cuando pasamos del «mundo vacío» al «mundo lleno»: la pregunta ya no es «cómo satisfacer un abastecimiento siempre en aumento de recursos naturales», sino más bien: ¿cuáles son los límites biosféricos en lo que se refiere a fuentes - de recursos naturales y energía - y a sumideros - de residuos y contaminación-, y cómo ajustamos el impacto humano (autorregulando nuestra población, nuestra tecnología, nuestras prácticas sociales y nuestras ideas sobre la vida buena) de manera que permanezcamos dentro de esos límites? Como se ve, la inversión de perspectiva es completa.

Otra manera de aproximarse a la misma idea: en un «mundo lleno», la idea de soberanía del consumidor es anacrónica. En lugar de ello, los poderes públicos democráticos deben diseñar estrategias de gestión de la deman$d a$ (no sólo en sectores donde la idea ya es de uso corriente, como el uso de energía o de agua, sino también en otros donde aún no ha penetrado esta nueva perspectiva: los transportes, el consumo de carne y pescado, el uso de recursos minerales, etc.) para no superar los límites de sustentabilidad, preservando al mismo tiempo en todo lo posible la libertad de opción.

En definitiva, lejos de hallarnos ante los problemas «ingenieriles» de conseguir siempre más agua, energía, alimentos, sistemas de eliminación de residuos, etc., en realidad tenemos sobre todo que resolver problemas filosóficos, políticos y económicos que se refieren a la autogestión colectiva de

Esto último es sin duda importante, en un país donde la productividad laboral casi se ha estancado desde 1996 (con crecimientos en torno a un magro 0,5\% anual). Se confía en que una política decidida de aumento de la productividad laboral conducirá a reducir los costes laborales unitarios, aumentar la competitividad y con ella las ventas de las empresas, y por esta vía consolidar y hacer crecer el empleo. Ahora bien: hay que insistir en que todavia más se ha descuidado, y no durante - años, sino durante decenios, la productividad del factor naturaleza: la eficiencia con la que empleamos los materiales y la energía para producir bienes y servicios. Producir ecológicamente requiere no buscar siempre los incrementos de productividad del trabajo humano a costa de una baja productividad de la energía y las materias primas y una alta intensidad de capital. En cualquier estrategia de desarrollo sostenible seria, ha de dedicarse un enorme esfuerzo a mejorar la productividad del factor naturaleza: de ahí los objetivos de «factor cuatro» $y$ «factor diez», para acercarnos a los cuales precisamos un esfuerzo de $I+D$ en ecoeficiencia acrecentado y reorientado. 1979.

${ }^{21}$ C. B. MacPherson, La teoría política del individualismo posesivo, Barcelona, Fontanella, 
las necesidades y los medios para su satisfacción. En un «mundo lleno», no se trata ya de un (imposible) aumento indefinido de la oferta, sino de una gestión global de la demanda.

\section{Apropiación justa en un «mundo lleno»}

Pensemos también en los criterios de apropiación justa que desarrolló la filosofía política occidental. El lugar clásico al respecto es la reflexión de John Locke, quien sentó las bases de la teoría liberal de la propiedad. Como es sabido, el principio fundamental propuesto por Locke es el derecho del autor a su obra, que remite a la idea del hombre como ser propietario: propietario de sí mismo, en cuerpo y alma, y de cuanto haga, produzca u obtenga con su cuerpo y su alma (es la figura del individualismo posesivo que C.B. MacPherson analizó profundamente ${ }^{21}$ ). Locke insiste una y otra vez en que «el trabajo de su cuerpo y la obra de sus manos son propiedad suya» 22 (del ser humano), en la medida en que el trabajo mezcla los dones de la naturaleza con el esfuerzo físico e intelectual humano. Ahora bien, cabe preguntarse en seguida, ¿cuáles son las condiciones para que la apropiación resultante de ese trabajo humanizador de la naturaleza resulte justa? Locke establece tres cláusulas de apropiación justa, una de las cuales es la que nos interesa aquí. Dice así: «Esta apropiación es válida cuando existe la cosa en cantidad suficiente y quede de igual calidad en común para los otros» ${ }^{23}$.

Salta a la vista que se trata de una condición pensada para el «mundo vacío»: Locke siempre pensó en la infinitud de la naturaleza, porque en su época, como decía, existían amplias extensiones de tierra sin ser explotadas. Así, para el pensador inglés, la privatización absoluta de la tierra en la Europa del XVII no incumplía la regla de aplicación justa, puesto que aún quedaban tierras vírgenes en América.

«La regla de apropiación, es decir, que cada hombre posea tanto cuanto pueda aprovechar, podía seguir siendo válida en el mundo, sin que nadie se sintiera estrecho y molesto, porque hay en él tierra bastante para mantener al doble de sus habitantes, si la invención del dinero, y el acuerdo tácito de los hombres de atribuirle un valor, no hubiera introducido (por consenso) posesiones mayores y un derecho a ellas» ${ }^{24}$.

En un «mundo lleno», no quedan ya tierras vírgenes por explotar, y caen las bases de la teoría liberal de la apropiación justa. En un planeta finito cuyos límites se han alcanzado, ya no es posible desembarazarse de los efectos indeseados de nuestras acciones (por ejemplo, la contaminación) desplazándolos a otra parte: ya no hay «otra parte». Una vez hemos «llenado el mun-

${ }^{22}$ John Locke, Segundo tratado sobre el gobierno civil, sección 27.

${ }^{23}$ Ibid., sección 27.

24 John Locke, Segundo tratado sobre el gobierno civil, sección 36. 
do», volvemos a hallarnos de repente delante de nosotros mismos: recuperamos de alguna forma la idea kantiana de que en un mundo redondo nos acabamos encontrando. Por eso, en la era de la crisis ecológica global, la filosofía, las ciencias sociales y la política entran en una nueva fase de acrecentada reflexividad. Y la humanidad debe hacer frente a una importante autotransformación... que acaso puede ser iluminada por el ciclo vital de una humilde ameba.

\section{LA AVENTURA DE LA AMEBA DICTYOSTELIUM DISCOIDEUM}

Los desarrollos exponenciales tienen necesariamente un límite. El desarrollo tecnológico de la humanidad acaba de alcanzar ese límite. Su desarrollo demográfico lo alcanzará antes de un siglo, situación comparable a la aventura de la ameba Dictyostelium discoideum. Cuando el medio le aporta alimentación suficiente, cada ameba, unicelular, vive y se reproduce por su propia cuenta, en competencia con las otras. Pero si este medio es limitado, la expansión de la colonia agota las riquezas que aquél aporta. La falta de alimento y de espacio provoca entonces una modificación radical. Las células se reúnen para formar sólo un ser único; luego se diferencian, unas constituyendo la base de ese ser, las otras el equivalente de su cabeza. Si el medio se vuelve más favorable, esta cabeza se abre para difundir esporas que se reconvertirán en amebas aisladas, y el ciclo recomienza.

En un planeta que se pudiera considerar como infinito, inagotable, el espléndido aislamiento de los egoísmos, individuales o colectivos, sería posible. En nuestro planeta cada vez más pequeño, de recursos no renovados, esta actitud es suicida para todos. Nos hace falta, como a la ameba, reunirnos para formar un ser único. Pero, al contrario que la ameba, no tenemos ninguna esperanza de ver un día ensancharse y enriquecerse nuestro medio. Estamos definitivamente condenados a la solidaridad de las células de un mismo ser. No cabe alegrarse de ello ni deplorarlo: hay que sacar consecuencias. (...) Desde mañana, la humanidad debe ser diferente de lo que era ayer, del mismo modo que el hombre adulto se diferencia del niño ${ }^{25}$.

\section{Un mundo sin alrededores}

Nuestro «mundo lleno», que es un mundo vulnerable ${ }^{26}$, ha de ser pensado también como un mundo sin alrededores, según la acertada sugerencia de Daniel Innerarity. Para el profesor de Zaragoza, todas las explicaciones que se ofrecen para aclarar lo que significa la globalización se contienen en la metáfora de que el mundo se ha quedado sin alrededores, sin márgenes, sin afueras, sin extrarradios. Global es lo que no deja nada fuera de sí, lo que contiene todo, vincula e integra de manera que no queda nada suelto, aisla-

\footnotetext{
${ }^{25}$ Albert Jacquard: Éste es el tiempo del mundo finito, Madrid, Acento, 1994, p. 144.

${ }^{26}$ Jorge Riechmann, Un mundo vulnerable, op. cit.
} 
do, independiente, perdido o protegido, a salvo o condenado, en su exterior. $\mathrm{El}$ «resto del mundo» es una ficción o una manera de hablar cuando no hay nada que no forme de algún modo parte de nuestro mundo común. No hay alrededores, no hay «resto del mundo»: nos encontramos - hay que insistir en ello - cara a cara con todos los demás seres humanos, y regresan a nosotros las consecuencias de nuestros actos en un «efecto bumerán».

La mayor parte de los problemas que tenemos se deben a esta circunstancia o los experimentamos como tales porque no nos resulta posible sustraernos de ellos o domesticarlos fijando unos límites tras los que externalizarlos: destrucción del medio ambiente, cambio climático, riesgos alimentarios, tempestades financieras, emigraciones, nuevo terrorismo. Se trata de problemas que nos sitúan en una unidad cosmopolita de destino, que suscitan una comunidad involuntaria, de modo que nadie se queda fuera de esa suerte común. Cuando existían los alrededores había un conjunto de operaciones que permitian disponer de esos espacios marginales. Cabía huir, desentenderse, ignorar, proteger. Tenía algún sentido la exclusividad de lo propio, la clientela particular, las razones de Estado. Y casi todo podía resolverse con la sencilla operación de externalizar el problema, traspasarlo a un «alrededor», fuera del alcance de la vista, en un lugar alejado o hacia otro tiempo. Un alrededor es precisamente un sitio donde depositar pacíficamente los problemas no resueltos, los desperdicios, un basurero. (...) Tal vez pueda formularse con esta idea de la supresión de los alrededores la cara más benéfica del proceso civilizador y la línea de avance en la construcción de los espacios del mundo común. Sin necesidad de que alguien lo sancione expresamente, cada vez es más difícil «pasarle el muerto» a otros, a regiones lejanas, a las generaciones futuras, a otros sectores sociales. Esta articulación de lo propio y lo de otros plantea un escenario de responsabilidad que resumía muy bien un chiste de El Roto: «En un mundo globalizado es imposible intentar no ver lo que pasa mirando para otro lado, porque no lo hay ${ }^{27}$ ».

Benjamin R. Barber, el catedrático de la Universidad de Maryland, ha desarrollado en varias de sus obras recientes las consecuencias políticas de la nueva interdependencia humana. En un mundo donde interior y exterior de las fronteras nacionales tienden a confundirsê, donde las crisis de la ecología, la salud pública, los mercados, la tecnología o la política acaban afectando a todos, «la interdependencia es una cruda realidad de la que depende la supervivencia de la especie humana» ${ }^{28}$. En un «mundo lleno», nos enfrentamos a la inaplazable necesidad de reinventar lo colectivo.

\section{La idea de biomímesis}

Hasta aquí hemos explorado los cambios que supone vivir en un «mundo lleno», y sugerido que la manera adecuada de reaccionar a esta nueva situa-

${ }^{27}$ Daniel Innerarity: «Un mundo sin alrededores», El Correo, 23 de mayo de 2004.

28 Benjamin R. Barber, «El día de la interdependencia», El País, 10 de septiembre de 2004. 
ción puede ser tomarnos en serio un principio de gestión generalizada de la demanda. Pasemos ahora a explorar otro de los cuatro rasgos básicos de nuestra situación que apunté al principio de esta conferencia - vivimos en una tecnosfera mal diseñada-, y el concomitante principio de biomímesis.

Desde hace decenios, ecólogos como Ramón Margalef, H. T. Odum o Barry Commoner han propuesto que la economía humana debería imitar la «economía natural» de los ecosistemas. El concepto de biomímesis (imitar la naturaleza a la hora de reconstruir los sistemas productivos humanos, con el fin de hacerlos compatibles con la biosfera) recoge esta estrategia, y, a mi entender, le corresponde un papel clave a la hora de dotar de contenido a la idea más formal de sustentabilidad ${ }^{29}$. Lo expuse ya, hace algunos años, en un capítulo de mi libro Un mundo vulnerable ${ }^{30}$; lo desarrollé más en el capítulo titulado «Biomímesis» del libro colectivo Industria como naturaleza, al que remito para ampliar las sucintas consideraciones que siguen ${ }^{31}$.

El término biomímesis se usó, en los años noventa, dentro de disciplinas como la robótica, las ciencias de materiales, o la investigación cosmética, con un sentido más restringido que el que propongo yo aquí. Así, por ejemplo, cabe estudiar la locomoción de los insectos con vistas a desarrollar robots hexápodos que funcionen correctamente. La idea entre los investigadores de tales disciplinas ha sido más la imitación de organismos (o partes de éstos) que la imitación de ecosistemas (sin embargo, este último es el objetivo que, a mi entender, hemos de plantearnos primordialmente).

Allende esta biomimética ingenieril, podemos tomar el principio de biomímesis en un sentido más amplio: se tratará, entonces, de comprender los principios de funcionamiento de la vida en sus diferentes niveles ( $\mathrm{y}$ en particular en el nivel ecosistémico) con el objetivo de reconstruir los sistemas humanos de manera que encajen armoniosamente en los sistemas naturales.

No es que exista ninguna agricultura, industria o economía «natural»: sino que, al tener que reintegrar la tecnosfera en la biosfera, estudiar cómo funciona la segunda nos orientará sobre el tipo de cambios que necesita la primera. La biomímesis es una estrategia de reinserción de los sistemas humanos dentro de los sistemas naturales.

Ya a mediados de los años noventa, la idea de ecomímesis había avanzado lo suficiente como para plasmarse en un sólido manual ${ }^{32}$. Janine M. Benyus, la investigadora que lo escribió (popularizando así el término biomi-

\footnotetext{
29 Aunque los origenes del concepto son anteriores, la palabra ecomímesis se acuñó, creo, a mediados de los años noventa. Un artículo seminal es el de Gil Friend: «Ecomimesis: copying ecosystems for fun and profit», The New Bottom Line, 14 de febrero de 1996, que puede consultarse en http://www.natlogic.com/resources/nbl/v05/n04.html.

30 Jorge Riechmann, Un mundo vulnerable, op. cit., pp. 117-118.

31 Estefanía Blount, Luis Clarimón, Ana Cortés, Jorge Riechmann y Dolores Romano (coords.) Industria como naturaleza. Hacia la producción limpia, Madrid, Los Libros de la Catarata, 2003.

32 Janine M. Benyus, Biomimicry: Innovation Inspired by Nature, Nueva York, William Morow, 1997. Véase al respecto la página web www.biomimicry.org
} 
micry en el mundo de habla inglesa), destaca que los sistemas naturales tienen las siguientes diez propiedades interesantes:

1. Funcionan a partir de la luz solar.

2. Usan solamente la energía imprescindible.

3. Adecuan forma y función.

4. Lo reciclan todo.

5. Recompensan la cooperación.

6. Acumulan diversidad.

7. Contrarrestan los excesos desde el interior.

8. Utilizan la fuerza de los límites.

9. Aprenden de su contexto.

10. Cuidan de las generaciones futuras.

La naturaleza, «la única empresa que nunca ha quebrado en unos 4.000 millones de años», según el biólogo Frederic Vester, nos proporciona el modelo para una economía sustentable y de alta productividad. Los ecosistemas naturales funcionan a base de ciclos cerrados de materia, movidos por la energía del sol: ésta es su característica fundamental, si los contemplamos con «mirada económica».

Se trata de una «economía» cíclica, totalmente renovable y autorreproductiva, sin residuos, y cuya fuente de energía es inagotable en términos humanos: la energía solar en sus diversas manifestaciones (que incluye, por ejemplo, el viento y las olas). En esta economía cíclica natural cada residuo de un proceso se convierte en la materia prima de otro: los ciclos se cierran. Por el contrario, la economía industrial capitalista desarrollada en los últimos dos siglos, considerada en relación con los flujos de materia y de energía, es de naturaleza lineal: los recursos quedan desconectados de los residuos, los ciclos no se cierran.

\section{¿Falacia naturalista?}

Hay una objeción que surge de inmediato frente a las estrategias de biomímesis: ¿estamos de alguna forma reactualizando la viejísima tradición de derecho natural o éticas de cuño naturalista, que pretenden deducir valores del mundo natural o ciertos rasgos del mismo, incurriendo así en lo que los filósofos llaman «falacia naturalista»?

No es el caso. Se trata de imitar la naturaleza no porque sea una «maestra moral», sino porque funciona. La biosfera es un «sistema de ecosistemas» perfectamente ajustado después de varios miles de millones de años de rodaje, autorreparación, reajuste darwiniano continuo y adaptación mutua - (coevolución) de todas las piezas de todos los complejísimos mecanismos; no es estática, pero se mantiene en una estabilidad dinámica merced a sutiles 
mecanismos de retroalimentación negativa que los cibernéticos saben apreciar en su justo valor. No es que lo natural supere moral o metafisicamente a lo artificial: es que lleva más tiempo de rodaje.

\section{Seis principios básicos de sustentabilidad}

A partir de la biomímesis, del funcionamiento de los ecosistemas, podemos sugerir seis principios básicos para la reconstrucción ecológica de la economía (aunque no tengo aquí espacio para derivarlos de manera más rigurosa):

1. ESTADO ESTACIONARIO en términos biofísicos.

2. VIVIR DEL SOL como fuente energética.

3. CERRAR LOS CICLOS de materiales.

4. NO TRANSPORTAR DEMASIADO LEJOS los materiales.

5. EVITAR LOS XENOBIÓTICOS como COP (contaminantes orgánicos persistentes), OMG (organismos transgénicos)...

6. RESPETAR LA DIVERSIDAD.

Ciclos de materiales cerrados, sin contaminación y sin toxicidad, movidos por energía solar, adaptados a la diversidad local: ésta es la esencia de una economía sustentable. Cuando se trata de producción industrial, suele hablarse en este contexto de producción limpia.

A todos los niveles la biomímesis parece una buena idea socioecológica y económico-ecológica:

- ecología industrial, remedando los ciclos cerrados de los materiales en la biosfera;

- agroecosistemas mucho más cercanos a los ecosistemas naturales que la actual agricultura industrial quimizada;

- biotecnología ambientalmente compatible, con biomoléculas artificiales donde sea preciso, pero guiándonos por el proceder de la misma naturaleza, etc.

Hay que indicar, por último, que la idea de biomímesis está estrechamente relacionada con el principio de precaución (el cuarto de los principios para la reconstrucción ecológica de los sistemas humanos que propuse al comienzo de este artículo): para apartarnos de los «modelos» de la naturaleza necesitamos razones mucho más fuertes, y conocimiento mucho más fiable, que para seguirlos.

Esto implica sofrenar el optimismo tecnológico que ha caracterizado la historia de las sociedades industriales, y ser capaces de entender la historia como un aprendizaje al que hay que sacar partido. Sabemos que los privilegiados de este mundo hemos de reducir nuestro impacto ambiental en un factor aproximadamente de diez: es decir, reducir a la décima parte nuestro 
consumo de energía y materiales, liberando así espacio ambiental para que puedan vivir decentemente los seres humanos del Sur, y el resto de los seres vivos con los que compartimos la biosfera. Una parte de estas reducciones pueden lograrse mediante una «revolución de la ecoeficiencia», pero no será suficiente: ha de completarse con una «revolución de la suficiencia», y eso quiere decir modificar pautas de comportamiento, ideas y valores. Precisamos un «factor diez» ético-político, además del «factor diez» en ecoeficiencia que ya se formuló como objetivo en los años noventa del siglo XX. Aquí la educación ambiental puede desempeñar un papel clave.

\section{Para recapitular: gestión global de la demanda y biomímesis}

Seguramente vale la pena acercarnos a la conclusión ofreciendo, en la sucinta formulación de una serie de tesis, algunas ideas que ya no será posible desarrollar más en el limitado espacio de este artículo, pero que he intentado explorar en otros trabajos.

1. Mientras existan seres humanos, existirán tecnosferas, es decir, el conjunto de artefactos producidos por los seres humanos para satisfacer sus necesidades y deseos a partir de los recursos que ofrece el medio ambiente: somos esencialmente homo faber.

2. Ahora bien, contra cualquier tentación de sucumbir al determinismo tecnológico, importa subrayar que son posibles muchas tecnosferas, que algunas de ellas son preferibles y otras francamente indeseables, y que nos importa mucho controlar democráticamente el proceso de modificación de la tecnosfera. «Otras tecnosferas son posibles», podíamos decir, remedando el conocido lema del Foro Social Mundial de Porto Alegre.

3. Hoy, la tecnosfera que prevalece en las sociedades industriales (y que tiende a extenderse al planeta entero) encaja mal con la biosfera que la contiene. Apreciamos incompatibilidades entre ambas; podríamos decir, con la gráfica metáfora de Barry Commoner, que la tecnosfera «está en guerra» con la biosfera (de donde resulta una crisis ecológica global cuya importancia resulta imposible exagerar) ${ }^{33}$.

4. La biosfera no es producible por medios técnicos (tal y como mostró el experimento Biosfera II en 1991-1993, aquella especie de enorme terrario construido en Arizona por científicos estadounidenses ${ }^{34}$ ), ni tampoco tras-

33 Barry Commoner, En paz con el planeta, Barcelona, Crítica, 1992, p. 15.

34 En septiembre de 1991, ocho investigadores se encerraron en Biosfera II, un invernadero hermético de 1,25 hectáreas construido en el desierto de Arizona, en cuyo interior se habían creado mini-ecosistemas. El intento de hacer funcionar aquello durante dos años sin ningún intercambio con el exterior (aparte el flujo de luz solar) fracasó: la degeneración de los ecosistemas artificiales - fue rápida, y hubo que bombear oxígeno desde el exterior para, a trancas y barrancas, mantener al equipo investigador dentro del invernadero durante dos años. Puede verse una información sucinta en Thomas Prugh y Erik Assadourian, «¿Qué es la sostenibilidad?», Worldwatch, 20 (ed. españo- 
cendible: no cabe pensar razonablemente en abandonarla para partir a la conquista de otros planetas ${ }^{35}$.

5. Si la tecnosfera «está en guerra» contra la casa común que es la biosfera, y esta última no podemos abandonarla ni crear otra de recambio, entonces la gran cuestión - a la que no resulta exagerado caracterizar como «el tema de nuestro tiempo»- es: ¿cómo rediseñar la tecnosfera, o las tecnosferas, de manera que encajen armoniosamente dentro de la biosfera?

Al tratar de responder a esta decisiva pregunta, veremos que en realidad aparecen dos dimensiones del problema: una de escala, y otra de estructura. Sistemas socioeconómicos humanos demasiado grandes en relación con la biosfera que los contiene, por una parte; y sistemas mal adaptados, sistemas humanos que encajan mal en los ecosistemas naturales. El problema de escala reclama un movimiento de autolimitación por parte de las sociedades humanas, que podríamos concebir (en términos de economía política) bajo la idea de gestión global de la demanda, y cuyas dimensiones ético-políticas he tratado de explorar estos últimos años en mi «trilogía de la autocontención» ${ }^{36}$; el problema de estructura exige una reconstrucción de la tecnosfera de acuerdo con principios de ecomímesis o biomímesis ${ }^{37}$.

\section{Romper la ficción de la normalidad}

¿Qué nos hace falta para cambiar hacia un mundo socialmente justo y ecológicamente sostenible? Sobre todo, recobrar el sentido de lo excepcional, la intuición de lo extraordinario. Volver a cobrar conciencia de lo milagroso en las obras humanas y lo milagroso en la naturaleza.

La improbable maravilla de que al apretar el interruptor se encienda la luz eléctrica (con todo el laborioso esfuerzo humano y la trabajosa historia humana que hay detrás); y la improbable maravilla de que una veintena de aves acuáticas de distintas especies coexistan con bullicioso júbilo en una marisma (con toda la vasta historia natural y toda la diversa interconexión biológica que hay detrás). En la intersección de esas dos clases de milagros puede florecer el punto de vista, el temple moral y la vida emotiva que posibiliten sociedades humanas sostenibles.

la), Madrid, 2004, pp. 10-11. También Dorion Sagan, Bioferas, Madrid, Alianza, 1995, pp. 251 ss. (el original inglés es de 1990).

${ }_{35}$ Argumenté en este sentido en Gente que no quiere viajar a Marte (Madrid, Los Libros de la Catarata, 2004). Véase en el mismo sentido Albert Jacquard, Éste es el tiempo del mundo finito, Madrid, Acento, 1994, «Introducción».

${ }^{36}$ Jorge Riechmann, Un mundo vulnerable, Madrid, Los Libros de la Catarata, 2000. Todos los animales somos hermanos, Universidad de Granada, 2003. Gente que no quiere viajar a Marte, Madrid, Los Libros de la Catarata, 2004.

${ }^{37}$ Jorge Riechmann, «Biomímesis: el camino hacia la sustentabilidad», capítulo 2 de Estefanía Blount, Luis Clarimón, Ana Cortés, Jorge Riechmann y Dolores Romano (coords.), Industria como naturaleza. Hacia la producción limpia, Madrid, Los Libros de la Catarata, 2003. 
Daré dos ejemplos. El primero viene de la estupenda autobiografía del escritor israelí Amos $\mathrm{Oz}$, Una historia de amor y oscuridad: telefonear hace seis decenios tenía indudablemente algo milagroso.

Yo podía ver físicamente ese único hilo que unía Jerusalén con Tel Aviv y, a través de él, con el mundo entero, y esa línea estaba ocupada y, mientras estaba ocupada, nosotros estábamos aislados del mundo. Ese hilo serpenteaba por zonas desérticas y pedregales, escalaba montañas y colinas, y yo pensaba que era un gran milagro. Me estremecía: ¿y si una noche los animales salvajes se comieran el hilo? ¿O si unos árabes malos lo cortasen? ¿O si se mojara con la lluvia? ¿Y si se prendieran las hierbas secas? Quién sabe. Una línea tan débil serpenteando por ahí, vulnerable, sin protección, abrasada bajo el sol. Quién sabe. Estaba muy agradecido a las audaces y hábiles personas que la habían tendido, pues no era tan sencillo tender una línea de Jerusalén a Tel Aviv; sabía por experiencia lo difícil que les habría resultado: una vez tendimos un hilo desde mi habitación hasta la de Elías Friedmann, una distancia de dos casas y un patio en total, un hilo normal y corriente, y vaya historia, árboles en el camino, vecinos, un almacén, una tapia, escaleras, arbustos... ${ }^{38}$

Mi segundo ejemplo es el final de otro libro notable, Una breve historia de casi todo del gran divulgador científico Bill Bryson. También estar vivo sobre esta Tierra tiene algo de milagroso:

Si estuvieses diseñando un organismo para que se cuidase de la vida en nuestro cosmos solitario, para controlar hacia dónde va y mantener un registro de dónde ha estado, no deberías elegir para la tarea seres humanos [por su extraordinaria destructividad].

Pero hay aquí un punto sumamente importante: hemos sido elegidos, por el destino, por la providencia o como quieras llamarle. Somos, al parecer, lo mejor que hay. Y podemos ser todo lo que hay. Es una idea inquietante que podamos ser el máximo logro del universo viviente $\mathrm{y}$, a la vez, su peor pesadilla.

Como somos tan notoriamente descuidados en to de cuidar de los seres, cuando están vivos y cuando no lo están, no tenemos idea (realmente ninguna en absoluto) de cuántas especies han muerto definitivamente, o pueden hacerlo pronto, o nunca.

(...) Somos terriblemente afortunados por estar aquí... y en el «somos» quiero incluir a todos los seres vivos. Llegar a generar cualquier tipo de vida, sea la que sea, parece ser todo un triunfo en este universo nuestro. (...) Los humanos conductualmente modernos llevamos por aquí sólo un 0'0001\% más o menos de la historia de la Tierra... Casi nada, en realidad, pero incluso existir durante ese breve espacio de tiempo ha exigido una cadena casi interminable de buena suerte ${ }^{39}$.

No vivimos tiempos «normales», sino tiempos excepcionales. De ahí la necesidad de abrir los ojos, cobrar conciencia de la crisis, romper la ficción

${ }^{38}$ Amos Oz, Una historia de amor y oscuridad, Madrid, Siruela, 2004, p. 18.

39 Bill Bryson, Una breve historia de casi todo, Barcelona, RBA, 2004, pp. 455-456. 
de la normalidad. En este sentido, no cabe duda de que les incumbe una especial responsabilidad a las autoridades públicas y a los «creadores de opinión».

\section{Los problemas medioambientales son problemas socioecológicos}

Los problemas medioambientales son en realidad problemas socioecológicos: la sociedad no conseguirá solucionar grandes amenazas como el cambio climático, la pérdida de biodiversidad, la degradación del territorio, la contaminación química o los impactos de los modelos de producción y consumo limitándose a buscar soluciones que mejoren el medio ambiente, sino a través de políticas - complejas, integradas, multidimensionales - que tengan en cuenta a la vez las implicaciones sociales, económicas y ecológicas. Este es el desafío implícito en el concepto de desarrollo sostenible, que con demasiada frecuencia se trivializa o malinterpreta.

El cambio de perspectiva esencial estriba en reconocer que el medio ambiente no forma parte de la economía, sino que la economía forma parte del medio ambiente. Son los subsistemas económicos humanos los que han de integrarse en el sistema ecológico englobante, y no al revés. Ésa es la clave para plantear adecuadamente los problemas de sostenibilidad.

\section{Sustentabilidad es revolución}

En una carta de propaganda comercial leemos: «Porque sabemos que usted siempre apuesta por tenerlo todo y tener lo mejor, queremos darle mucho más». Querer tenerlo todo; por añadidura, querer tener lo mejor; y como guinda de la tarta, querer aún mucho más. ¡Qué mortífera bulimia! Quienes así disponen los lazos y las trampas son los destructores de este mundo. Son los descreadores de la Tierra.

Cuando se habla de cantidad y calidad, esta cultura bulímica nuestra tiende como siempre a la acumulación: calidad a la vez que sigue aumentando la cantidad. Pero de lo que se trata, quizá, es de que la creciente calidad compense la cantidad que ha de menguar.

«La economía moderna»-escribió hace más de treinta años Ernst F. Schumacher en ese clásico del pensamiento ecologista titulado Small is Beautiful - «procura elevar al máximo el consumo para poder mantener al máximo la producción. En vez de ello, deberíamos maximizar las satisfacciones humanas mediante un modelo de consumo óptimo (no máximo). El esfuerzo - social y ecológico - para mantener una forma de vida basada en un modelo óptimo de consumo es mucho menor que el necesario para mantener un consumo máximo». 
$¿$ Verdaderamente nuestros gobernantes y nuestros conciudadanos son incapaces de comprender la diferencia entre óptimos y máximos?

Cambiar las pautas de producción y consumo en el Norte (y con ellas, las pautas de trabajo y ocio, en definitiva: las formas de socialidad y las relaciones de producción), que es un mandato de la «Cumbre de la Tierra» de Johannesburgo (verano de 2002) y también una exigencia histórica inesquivable, son palabras mayores. Sustentabilidad es revolución, se ha dicho, no sin veracidad.

Nuestro modelo de desarrollo (que es insostenible, a estas alturas casi huelga decirlo) se basa en la exportación de daño. No tanto en la organización racional de la producción, ni en la aplicación de la ciencia a la misma, ni en la explotación de ventajas comparativas, ni en otras - reales o supuestas- buenas cualidades que nos complace evocar: se basa, sobre todo, en la exportación de daño (en el espacio - geográfico, ecológico, social- y en el tiempo).

Por eso, sin nuevas «reglas de juego» para la economía y la relación entre seres humanos y naturaleza, sin cambios radicales en nuestras normas y nuestras conductas orientados a transformar el metabolismo humanidad/ biosfera, los objetivos de justicia y sustentabilidad no serán sino cháchara insulsa. Ésta es la realidad que hemos de afrontar en el siglo XXI.

\section{La sostenibilidad no puede convertirse en la coartada del desarrollo}

Sostenibilidad no es, de forma general, hacer más (aunque en algunos ámbitos haya que hacer más: energías renovables o tecnologías ecoeficientes, por ejemplo). Se trata, sobre todo, de hacer distinto y también de hacer menos.

De ahí las dificultades políticas y sociales del asunto: añadir nos resulta fácil, autolimitarnos no. Pero tenemos que aprender a decir no colectivamente ante la terrible bulimia desarrollista.

El problema, hoy, es que la sostenibilidad se convierte en la coartada del desarrollo. El mecanismo es el siguiente: todo lo viejo insostenible continúa funcionando a toda marcha, al $150 \%$ podríamos decir, mientras que se añade a lo viejo una plétora de nuevos proyectos de desarrollo... sostenible.

Un buen ejemplo lo proporciona la candidatura olímpica de Madrid («Madrid 2012»). Ahora «se ha presentado un dossier ante el Comité Olímpico Internacional en el que diseña un crecimiento de su capacidad hotelera y describe además una capital articulada en torno al transporte público y la defensa del medio ambiente (autobuses de hidrógeno e instalaciones deportivas construidas con materiales ecológicos). [...] El plus de calidad de Madrid 2012 es una clara apuesta por el desarrollo sostenible... ${ }^{40}$ ». Tome usted ese feraz caldo de cultivo de la especulación inmobiliaria, la construcción de au-

\footnotetext{
${ }^{40}$ Mábel Galaz, «Madrid prevé ganar 6.000 millones con los Juegos Olímpicos de 2012», El País, Madrid, 21 de noviembre de 2004, pp. 1 y 4.
} 
topistas y el consumismo antiecológico que es Madrid, y añádale autobuses de hidrógeno y nuevas edificaciones construidas con criterios ecológicos (si es que al final se imponen de verdad tales criterios): al resultado llámelo «desarrollo sostenible».

$\mathrm{Y}$ todo se justifica en términos de empleo: en este caso se nos promete que los Juegos generarán 170.000 empleos. Qué razón tiene Albert Recio cuando advierte sobre la necesidad de cuestionar el mecanismo legitimador de la creación de empleo:

Hoy la generación de empleo legitima cualquier política económica. Aunque la obtención de beneficios privados es el criterio real de decisión económica, la creación de empleo constituye su mecanismo legitimador. El criterio de la creación de empleo neutraliza cualquier demanda de racionalidad ambiental o de condiciones de trabajo dignas. Seguir planteando el empleo como la principal prioridad social, a la que deben supeditarse las demás cuestiones, supone estar jugando permanentemente en un terreno hostil ${ }^{41}$.

¿Qué se hace cuando se descubre una incompatibilidad básica entre la sociedad industrial y la biosfera? O bien se profieren conjuros y encan-

${ }^{41}$ Albert Recio, «Empleo y medio ambiente. Necesidad y dificultad de un proyecto alternativo», ponencia en el curso de verano de la UCM «Nuevas economías: una alternativa ecológica», San Lorenzo del Escorial, 19 al 23 de julio de 2004. En la misma ponencia, el economista y dirigente vecinal catalán sugiere tomar las necesidades humanas como punto de partida. «Una política económica de izquierdas debe empezar por plantear la actividad económica desde la óptica de las necesidades. [...] Plantear la organización económica desde el punto de vista de las necesidades supone empezar por discutir cuáles son los niveles de vida que deben garantizarse universalmente, en el sentido propuesto por Doyal y Gough (1987), de permitir a todos los ciudadanos participar normalmente de la vida social. Este enfoque permite también abrir un debate social sobre lo que es básico, lo que es secundario, lo que es un lujo y lo que resulta totalmente inaceptable por los efectos negativos, sociales y ambientales, que provoca en la sociedad. Permite también discutir entre formas alternativas de satisfacer necesidades básicas y romper el determinismo tecno-productivo con el que se defiende la continuidad de las formas actuales de vida. Un enfoque de necesidades conduce a la priorización de actividades sociales y a la penalización (incluida la prohibición) de aquellas que generan un reconocido mal social. [...] Un enfoque de necesidades supone también considerar que la actividad laboral mercantil (o realizada para instituciones públicas) debe permitir el desarrollo de la vida personal y unas buenas condiciones de trabajo. Los problemas de encaje entre la actividad laboral mercantil, el trabajo doméstico y la vida social no tienen solución mientras la actividad mercantil siga hegemonizando la organización del tiempo vital. Plantear el trabajo desde este enfoque conduce sin duda a favorecer modelos de organización más cooperativos (y cualificadores). En parte, la nueva propuesta de la OIT a favor del trabajo decente, tratando de fijar condiciones mínimas en diversos campos (duración, paga, derechos sociales...), va en este mismo sentido. Supone entre otras cuestiones una lucha contra el subempleo y a favor de condiciones laborales básicamente igualitarias. De hecho, la cantidad total de empleo debería ser ajustable a través de cambios en la jornada laboral, cuya fijación debería obedecer a los cambios en la cantidad de trabajo necesaria para cubrirlas. $Y$ un enfoque de necesidades supone además reconocer que a través del mercado sólo se satisfacen una parte de las necesidades sociales. La actividad doméstica y social juega también un papel básico. Por esto la organización de los tiempos debe considerar prioritamente las lógicas temporales que emanan de las necesidades de reproducción social, cuestionando la actual primacía de la empresa privada en la organización del tiempo de vida». 
tamientos (sostenibilidad como retórica), o bien se emprende de manera firme una reconstrucción de la sociedad industrial (sostenibilidad como revolución).

La clave inexclusable del desarrollo sostenible es la autolimitación. Todo lo demás puede ayudar (ecoeficiencia, integración de políticas, etc.), pero lo único decisivo es la autolimitación. Y de es de autolimitación es de lo que nadie quiere oír hablar.

\section{Final}

«El crecimiento económico y la protección medioambiental no son incompatibles. El desarrollo sostenible es un motor de la creación de mercados y la generación de actividades como las referidas a la restauración ecológica», escribe José María Rey Benayas (profesor de Ecología de la Universidad de Alcalá) ${ }^{42}$.

Desde luego, destruir para luego reconstruir es un potentísimo motor para la actividad económica... Pero ¿la sustentabilidad a la que aspiramos puede identificarse con esa locura?

Para quienes hoy prevalecen, desarrollo sostenible quiere decir sustituir autos viejos por coches ecológicos, e instalar aparatos de aire acondicionado respetuosos con el medio ambiente. Para quienes resistimos, desarrollo sostenible quiere decir vivir bien sin coche y sin aire acondicionado.

Esto último exige - insisto de nuevo en ello- nada menos que reinventar lo colectivo. No hay forma de reducir drásticamente nuestro impacto sobre la biosfera, al mismo tiempo que aseguramos las condiciones favorables a una vida buena para cada ser humano, sin actuar profundamente sobre nuestra socialidad básica, desarrollándola y enriqueciéndola. Por eso el desarrollo sostenible, si nos lo tomamos de verdad en serio, implica antes que nada la exigencia de reinventar lo colectivo.

${ }^{42}$ «Degradación ambiental y restauración ecológica», Análisis madrid, 14 de octubre de 2004. 